\title{
Prescription of Sedative Drugs During Hospital Stay: A Swiss Prospective Study
}

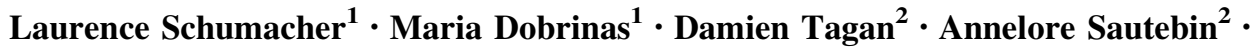 \\ Anne-Laure Blanc ${ }^{1} \cdot$ Nicolas Widmer ${ }^{1,3}$
}

Published online: 21 September 2017

(c) The Author(s) 2017. This article is an open access publication

\begin{abstract}
Background In recent years, the number of prescriptions for sedative drugs has increased significantly, as has their long-term use. Moreover, sedative use is frequently initiated during hospital stays.

Objectives This study aimed to describe new prescriptions of sedative drugs during hospital stays and evaluate their maintenance as discharge medication.

Methods This observational prospective study took place in an internal medicine ward of a Swiss hospital over a period of 3 months in 2014. Demographic (age, sex, diagnosis, comorbidities) and medication data [long-term use of sedative drugs, new regular or pro re nata ('as needed') prescriptions of sedative drugs, drug-related problems] were collected. Sedative medications included: benzodiazepines, Z-drugs, antihistamines, antidepressants, neuroleptics, herbal drugs, and clomethiazole. McNemar's test was used for comparison.

Results Of 290 patients included, $212(73 \%)$ were over 65 years old and $169(58 \%)$ were women; $34 \%(n=98)$ were using sedative drugs long term before their hospital stay, and $44 \%(n=128)$ had a prescription for sedative
\end{abstract}

Anne-Laure Blanc and Nicolas Widmer contributed equally to the supervision of this work.

Anne-Laure Blanc

annelaure.blanc@phel.ch

1 Clinical Pharmacy Services, Pharmacie des Hôpitaux de l'Est Lémanique, Boulevard Paderewski 3, 1800 Vevey, Switzerland

2 Internal Medicine Department, Hôpital Riviera-Chablais, Vaud-Valais, Vevey, Switzerland

3 Division of Clinical Pharmacology, Lausanne University Hospital, Lausanne, Switzerland drugs at discharge-a $10 \%$ increase $(p<0.05)$. Sedative drugs were newly prescribed to $37 \%(n=108)$ of patients during their stay. Among these, $37 \%(n=40)$ received a repeat prescription at discharge. Over half of the sedative drugs were prescribed within $24 \mathrm{~h}$ of admission. Drug-related problems were detected in $76 \%$ of new prescriptions, of which $90 \%$ were drug-drug interactions.

Conclusion This study showed that hospital stays increased the proportion of patients who were prescribed a sedative drug at discharge by $10 \%$ (absolute increase). These prescriptions may generate long-term use and expose patients to drug-related problems. Promoting alternative approaches for managing insomnia are recommended.

\section{Key Points}

Hospital stays increased the proportion of patients being prescribed a sedative drug by $10 \%$ by hospital discharge, thus potentially increasing the risk of long-term use.

Around half (52\%) of new sedative drug prescriptions were written within $24 \mathrm{~h}$ of hospital admission.

Sedative prescriptions during hospital stays expose patients to drug-related problems.

\section{Introduction}

Between 20 and $50 \%$ of the world's population experience sleep disorders, making them a major health problem [1, 2]. In USA, between 1993 and 2007, the number of 
prescriptions for sedative medications increased significantly (two-fold for benzodiazepines and 30-fold for nonbenzodiazepine sedative drugs), even faster than the number of medical consultations for sleep disorders (insomnia diagnoses increased up to seven-fold) [3].

In 2012, the Continuous Rolling Survey on Addictive Behaviors and Related Risks estimated that more than 220,000 people in Switzerland were using sedative drugs (i.e., $3 \%$ of inhabitants). Use was common in the geriatric population, and the number of prescriptions per person increased with age. In people over 70 years old, $11 \%$ of men and $21.5 \%$ of women were taking sedative drugs, with $5.3 \%$ of men and $9.1 \%$ of women having used sedative drugs almost daily for over 1 year [4].

Public health campaigns on this issue are conducted regularly. For instance, in 2013, the Swiss canton of Vaud conducted a regional prevention campaign entitled, "Sedatives? Not necessarily needed", which aimed to raise awareness among the population and physicians about the risks associated with sedative drug use [5].

Several adverse effects have been described for sedative drugs, such as drowsiness, delirium, nightmares, dizziness, falls, road traffic accidents, and depression, especially in elderly populations [6-9]. The elderly present a higher risk of developing severe side effects because their bodies eliminate drugs more slowly and are more sensitive to their effects. The elderly thus face increased risks of delirium, cognitive impairment, or falls [8, 10]. Moreover, long-term use of sedative drugs can decrease cognitive performance and generate problems of tolerance and dependence [7, 8]. Overall, using sedative drugs is associated with an increased risk of total mortality [11, 12], and thus their long-term prescription is not recommended [7]. Product monographs and guidelines advise short-term use and constant reassessment of prescribed sedative drugs [7, 13].

Sleep disorders are commonly observed during hospital stays because of patients' particular conditions, such as illness, pain, anxiety, an unusual living environment, or external night-time stimuli such as noises and lights $[6,14,15]$. Furthermore, many drugs can disrupt sleep, for example, antidepressants, beta-blockers, bronchodilators, corticosteroids, and neurological and psychotropic drugs $[15,16]$.

One study of Australia's general adult population described the prevalence, consequences, and treatment of insomnia. The prevalence of insomnia was $13-33 \%$ and the study referred to regular difficulties in either getting to or staying asleep [17]. Other studies reported a similar prevalence in the general population [18-20]. Moreover, studies conducted in hospitals have estimated the prevalence of benzodiazepine use at 20-45\% [21-23].

Sedative drugs are frequently first prescribed during a hospital stay and, among them, the prescription of benzodiazepines is commonplace [24, 25]. Ideally, these drugs should be withdrawn before patients are discharged, however, few data are available on the proportion of sedative drugs initiated in hospital settings and still found on patients' discharge prescriptions. The Swiss Society of General Internal Medicine recently identified five priority actions to promote smarter medicine, among which was limiting the use of benzodiazepines or other sedative drugs in older adults during hospital stays [26]. Similarly, in its Choosing Wisely campaign, the American Geriatric Society recommends not using benzodiazepines as first-line treatment for insomnia in older adults [27, 28]. To the best of our knowledge, only a few studies have suggested that hospitals have an influence on the ambulatory use of sedative drugs $[29,25,30,31]$. One French study showed that hospitals could have a significant impact on ambulatory sedative drug use, showing that $65 \%$ of sedative drugs prescribed during a hospital stay were still prescribed at discharge [30]. Another study showed that $43 \%$ of patients used sedative drugs during their hospital stay, and that $33 \%$ were still prescribed them at discharge [31]. Furthermore, patients, especially elderly individuals, are susceptible to drug-related problems (DRPs) linked to their ongoing medical treatment, such as potentially inappropriate prescriptions, incorrect dosages, contraindications, suboptimal treatment duration, duplicate therapy, drug-drug interactions, or other side effects. One study described how $95 \%$ of elderly patients presented with at least one DRP as a result of their treatment [32]. With regard to sedative drugs, another study showed that $77 \%$ of new benzodiazepine prescriptions during hospital stays were considered to be potentially inappropriate prescriptions [33]. Moreover, the use of benzodiazepines is considered as inappropriate in the STOPP/START tool for detecting potentially inappropriate prescriptions in the elderly [34]. The present study aimed to describe the prescription of new sedative drugs during hospital stays in an internal medicine ward and evaluate their maintenance as discharge medication.

\section{Methods}

\subsection{Setting and Participants}

The present study was descriptive, observational, prospective, and monocentric. It took place in the 70-bed internal medicine ward of a Swiss hospital (Hôpital Riviera-Chablais, Vaud-Valais). Patients were enrolled during the 3-month period from May to August 2014.

Every day, a clinical pharmacist identified potential participants via the hospital's administrative software (Opale ${ }^{\circledR}$, Version 6.8; Ordi-conseil SA, Lausanne, Switzerland). Patients admitted to the internal medicine 
ward were screened using the study inclusion criteria (aged 18 years or more, a hospital stay of more than $24 \mathrm{~h}$, the capacity of judgment, alive at discharge, proficiency in French, and informed consent).

\subsection{Outcomes and Variables}

The term 'sedative drugs' referred to all drugs with sedative properties administered for the treatment of sleep disturbances (including off-label use) after 6 p.m. (the usual evening medication administration time in our hospital). This included: benzodiazepines, benzodiazepine-related drugs (Z-drugs), antihistamines, antidepressants, neuroleptics, barbiturates and their derivatives, herbal drugs, and other sedative drugs (clomethiazole). Although the use of herbal drugs (such as valerian) is not evidence based, this drug is regularly used in our hospital in the attempt to limit the use of other sedative drugs.

The study was divided into three parts. The first part described the long-term use of sedative drugs and focused only on patients already taking them, whether pro re nata (PRN, or 'as needed') or regularly, before their hospital stay. These patients were identified during the eligibility assessment by using a short oral questionnaire on their prior consumption of sedative drugs. The questionnaire included items about: the type of sedative used (brand name and active ingredient), dosage, rate of use, and treatment duration for all the sedative drugs included in the study. The second part focused on the use of sedative drugs initiated during the hospital stay. All eligible patients were included and followed prospectively to identify any new sedative prescriptions. Demographic data (age, sex), clinical data (diagnosis, comorbidities), and the number of occupied beds in the room (a hypothetical reason for a sleep disorder) were noted. Diagnoses and comorbidities were subsequently classified into broader categories. Medication data (long-term use of sedative drugs, new prescriptions of sedative drugs, the prescriber, drug class, administrative data, prescription duration, DRPs, and the discharge prescription) were collected from patients' electronic medical records (Soarian ${ }^{\circledR}$, Version 3.04 SP12; Siemens Medical Solutions, Malvern, PA, USA). Information on new prescriptions of sedative drugs (during the hospital stay and at discharge) was collected from the hospital's computerized physician order entry system (Predimed $^{\circledR}$, Version 2.12.2; Lausanne University Hospital, Lausanne, Switzerland).

Part three focused on medication reviews to identify potential DRPs generated by new sedative prescriptions for patients already taking other long-term medication. Newly initiated sedative drugs were analyzed for potential DRPs according to the following criteria: duplicate therapy, contraindications, side effects, drug-drug interactions, drug dosages, or therapeutic adherence. Duplicate therapy was defined as the use of two or more sedative drugs from the same therapeutic class (e.g., two benzodiazepines). Overdosage (more than the dosage approved by Switzerland's official information drug regulatory agency), under-dosage (less than the approved amount), or inadequate dosage, according to the patient's physiological state (e.g., renal or hepatic insufficiency), were defined based on the recommendations found in the product information [7]. If dose data were missing or insufficient, Micromedex ${ }^{\circledR}$ (Truven Health Analytics, Ann Arbor, MI, USA) [35] and Lexicomp Online ${ }^{\circledR}$ (Lexicomp, Hudson, OH, USA) [8] were used. Lexi-Interact $^{\circledR}$ (Lexicomp, Hudson, OH, USA) [8] was used to check drug-drug interactions. As clomethiazole was not listed in these databases, interactions related to this drug were checked according to the product information and deduced from its mechanism of action and properties. Drug-related problems were identified with reference to the criteria used in previous studies defining DRPs [32, 36], as well as to the Swiss Association of Public Health Administration and Hospital Pharmacists' system for pharmaceutical interventions [37].

\subsection{Statistical Analysis}

Descriptive statistics (means, proportions, standard deviations, confidence intervals, and graphic representations) were calculated using Excel ${ }^{\circledR}$ (Version 2010; Microsoft Corp, Redmond, WA, USA). Chi-square tests for associations between variables and McNemar's test for 'before and after' comparisons were carried out using STATA ${ }^{\circledR}$ (Version 13.1; StataCorp, College Station, TX, USA), and $p$ values $>0.05$ were considered statistically significant.

\subsection{Ethics Approval}

This study was approved by the Human Research Ethics Committee of the Canton Vaud (Lausanne, Switzerland; approval ID: 112/14). Oral informed consent was obtained from each participant included in the study.

\section{Results}

\subsection{Study Population}

Of 425 patients assessed for eligibility, the study included 290 (Fig. 1); 212 (73\%) participants were aged over 65 years and $169(58 \%)$ were women. The most common diagnoses and comorbidities were cardiovascular $(68 \%)$, metabolic $(64 \%)$, urinary $(37 \%)$, rheumatic and pain (35\%), gastrointestinal (35\%), and neurological (34\%). Patients' characteristics, diagnoses, and comorbidities are described in Table 1. 
Fig. 1 Flow chart of participants

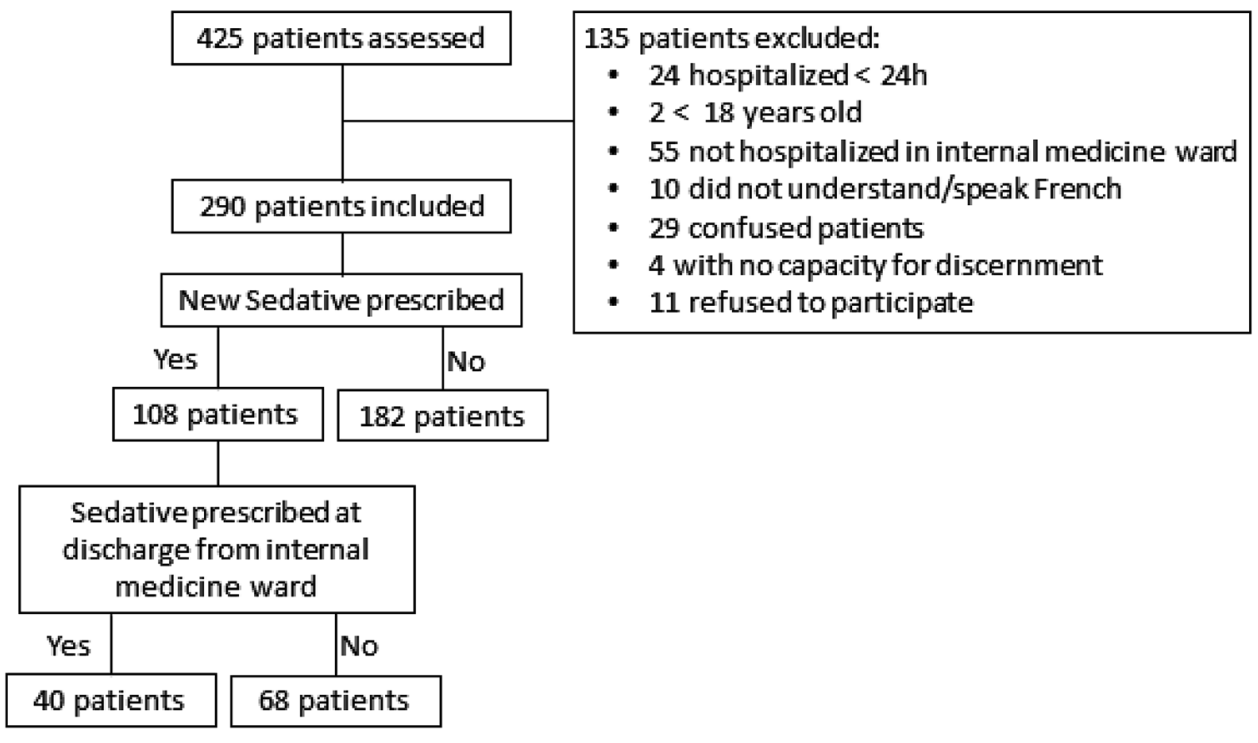

Table 1 Patients' characteristics $(n=290)$

\begin{tabular}{lc}
\hline Characteristics & $n(\%)$ \\
\hline Age (years) & \\
$<65$ & $78(27)$ \\
$65-84$ & $132(45)$ \\
$\geq 85$ & $80(28)$ \\
Sex & \\
Female & $169(58)$ \\
Male & $121(42)$ \\
Diagnoses and comorbidities & \\
Cardiovascular & $198(68)$ \\
Metabolic & $186(64)$ \\
Urinary & $106(37)$ \\
Rheumatic and pain & $102(35)$ \\
Gastrointestinal & $101(35)$ \\
Central or peripheral nervous system & $99(34)$ \\
Respiratory & $76(26)$ \\
Psychiatric & $67(23)$ \\
Infectious & $66(23)$ \\
Oncological & $58(20)$ \\
Hematological & $35(12)$ \\
Thromboembolic & $33(11)$ \\
Dermatological & $21(7)$ \\
Others & $17(6)$ \\
\hline
\end{tabular}

\subsection{Long-Term Use of Sedative Drugs}

Of the present study's 290 patients, 34\% $(n=98)$ had been taking sedative drugs long term before their hospital stays, and $74 \%$ were at least 65 years old $(41 \%$ were aged
65-84 years, $33 \%$ were older). Of the 98 patients taking sedative drugs long term, $78 \%$ agreed to answer the questionnaire about their long-term use ( $n=76$; two patients refused, 20 could not be questioned). Of the responders, $89 \%$ took one or two sedative medications long term and $11 \%$ took more than two drugs. The description of this long-term sedative medication use is presented in Table 2 .

\subsection{Sedative Drugs Initiated During Hospital Stay}

During their hospital stay, 62\% ( $n=180)$ of the study's patients were prescribed at least one sedative, including drugs that they were already prescribed, drugs newly initiated in hospital, or both. Sedative medications were initiated during hospitalization in $37 \%(n=108)$ of patients. Eighty-one patients were naive to these drugs, of whom $70 \%$ of patients $(n=76)$ were prescribed a single sedative. The total number of newly prescribed sedative drugs was 161. Of these, $68 \%$ were prescribed for use PRN, meaning that patients only took their sedative drug when needed. Over half $(52 \%)$ of the sedative drugs were prescribed within $24 \mathrm{~h}$ of admission, and $76 \%$ of prescriptions were not reassessed during the stay. Roughly half of sedative prescriptions $(47 \%)$ were given by the physician in charge of the patient. Most of the prescriptions for new sedative medications (76\%) were for patients over 65 years old.

With regard to comorbidities, univariate analyses showed that patients with psychiatric disorders were more likely to receive a new prescription for a sedative during their hospital stay $(p<0.05)$. Moreover, patients arriving at the hospital and whose usual treatment involved longterm sedative drugs were less likely to receive an additional sedative prescription during their hospital stay $(p<0.05)$. 
Table 2 Long-term use of sedative drugs prior to hospital stay $(n=76)$

\begin{tabular}{lc}
\hline Characteristics & $n(\%)$ \\
\hline Frequency of administration of the most commonly used sedative drug & \\
Every day & $50(66)$ \\
$1-4$ times a week & $16(21)$ \\
Less than once a week & $3(4)$ \\
Unknown & $7(9)$ \\
Duration of administration of the most commonly used sedative drug & \\
$\leq 1$ year & $19(25)$ \\
$>1$ year & $54(71)$ \\
Unknown & $3(4)$ \\
\hline
\end{tabular}

This table's results refer to the 76 patients who consented to answer the questionnaire, of the 98 patients taking sedative drugs long term
The number of occupied beds (range 1-4) in the patient's room had no influence on the prescription of sedative drugs $(p>0.05)$. The most commonly prescribed sedative drugs were benzodiazepines (47\%), however, the type of sedative drug was influenced by age (Table 3 ).

\subsection{Medication Review of New Sedative Drug Prescriptions}

A medication review was performed for $83 \%$ of the patients who received a new sedative prescription $(n=90$; the medication for 18 patients could not be analyzed because information on their treatments was missing on the day of prescription). Sometimes, new sedative drugs were prescribed on weekends or public holidays, and it was impossible to retrospectively determine the exact circumstances of those prescriptions on the next working day. Moreover, the computerized physician order entry system could not easily identify all the co-medications prescribed at that specific moment. We analyzed 117 new prescriptions, of which 89 (76\%) presented at least one DRP: $90 \%$ drug-drug interactions, $17 \%$ contraindications, $11 \%$ duplicate therapies, $7 \%$ inadequate dosage according to the physiological state, and $1 \%$ overdose. The most commonly identified drug-drug interactions are presented in Table 4.

\subsection{Sedative Drugs at Discharge}

A total of $44 \%(n=128)$ of patients received a prescription for sedative medication at the end of their hospital stay-a $10 \%$ increase compared with prescriptions at admission $(34 \%)$ [ $p<0.05]$. Among them, 98 had already received a sedative medication before hospitalization and 30 had a new sedative drug prescription at the discharge. In those patients who had been prescribed a new sedative drug during their hospital stay, 37\% $(n=40)$ had the same prescribed sedative medication at discharge. Table 5 summarizes the prescription of sedative drugs during hospital stays and at discharge. Table 6 presents the overall prevalence of one or more sedative drugs prescribed during hospital stays and at discharge. Univariate analyses revealed that several clinical factors were associated with an increased risk of being prescribed a sedative drug at discharge: psychiatric disorders $(p<0.05)$, oncological diagnoses $(p<0.05)$, and a regularly scheduled prescription of sedative drugs during the hospital stay $(p<0.05)$.

\section{Discussion}

\subsection{Long-Term Use of Sedative Drugs}

At hospital admission, 34\% of the present study's patients were using sedative medications long term. In two previous Belgian and Canadian studies (2003 and 2004, respectively), $29 \%$ of patients reported taking sedative drugs at home [17, 24]. A Danish study conducted in 2010 found similar results (30\%) [38]. These slight differences from our results might be owing to a global increase in the consumption of these drugs by the general population over the last 10 years.

In our study, $74 \%$ of patients using sedative drugs long term were aged 65 years and over, and $71 \%$ had been taking sedative drugs for at least 1 year. Guidelines for the prescription of sedative drugs recommend short treatment durations, not exceeding 4 weeks if possible [1, 13]. Moreover, the elderly are more subject to the side effects of these drugs, especially in cases of long-term use $[13,39,40]$. As in other studies, the present study confirmed that the patients most likely to be long-term users of sedative drugs were generally the older ones and that treatment durations were usually longer than recommended [13, 16, 29]. 
Table 3 Types of sedative drugs prescribed during hospital stay

\begin{tabular}{|c|c|c|c|c|}
\hline Sedative drugs & $\begin{array}{l}\text { Total } \\
(n=161) \\
n(\%)\end{array}$ & $\begin{array}{l}\text { Age }<65 \text { years } \\
(n=34) \\
n(\%)\end{array}$ & $\begin{array}{l}\text { Age } 65-84 \text { years } \\
(n=91) \\
n(\%)\end{array}$ & $\begin{array}{l}\text { Age } \geq 85 \text { years } \\
(n=36) \\
n(\%)\end{array}$ \\
\hline Benzodiazepines & $76(47)$ & $25(73)$ & $36(40)$ & $15(42)$ \\
\hline Lorazepam $\left(\right.$ Temesta $\left.^{\circledR}\right)$ & $31(19)$ & $12(35)$ & $16(18)$ & $3(8)$ \\
\hline Oxazepam $\left(\right.$ Seresta $\left.^{\circledR}\right)$ & 23 (14) & $8(23)$ & $9(10)$ & $6(17)$ \\
\hline Bromazepam (Lexotanil $^{\circledR}$ ) & $9(6)$ & $0(0)$ & $5(6)$ & $4(11)$ \\
\hline Midazolam (Dormicum ${ }^{\circledR}$ ) & $4(3)$ & $0(0)$ & $0(0)$ & $0(0)$ \\
\hline Diazepam $\left(\right.$ Valium $\left.^{\circledR}\right)$ & $3(2)$ & $3(9)$ & $4(4)$ & $0(0)$ \\
\hline Clorazepate $\left(\right.$ Tranxilium $^{\circledR}$ ) & $2(1)$ & $2(6)$ & $0(0)$ & $0(0)$ \\
\hline Alprazolam $\left(\right.$ Xanax $\left.^{\circledR}\right)$ & $2(1)$ & $0(0)$ & $0(0)$ & $2(6)$ \\
\hline Flurazepam (Dalmadorm ${ }^{\circledR}$ ) & $2(1)$ & $0(0)$ & $2(2)$ & $0(0)$ \\
\hline Z-drugs & $17(11)$ & $5(15)$ & $11(12)$ & $1(3)$ \\
\hline Zolpidem $\left(\right.$ Stilnox ${ }^{\circledR}$ ) & $14(9)$ & $4(12)$ & $9(10)$ & $10(3)$ \\
\hline Zopiclone (Imovane ${ }^{\circledR}$ ) & $3(2)$ & $1(3)$ & $2(2)$ & $0(0)$ \\
\hline Other sedative drugs & $51(32)$ & $3(9)$ & 34 (37) & $14(39)$ \\
\hline \multicolumn{5}{|l|}{ Clomethiazole (Distraneurin ${ }^{\circledR}$ ) } \\
\hline Antidepressants & $6(4)$ & $1(3)$ & $2(2)$ & $3(8)$ \\
\hline Trazodone $\left(\right.$ Trittico $\left.^{\circledR}\right)$ & $1(1)$ & $0(0)$ & $1(1)$ & $0(0)$ \\
\hline Mirtazapine $\left(\right.$ Remeron $^{\circledR}$ ) & $5(3)$ & $1(3)$ & $1(1)$ & $3(8)$ \\
\hline Neuroleptics & $5(3)$ & $\mathbf{0}(\mathbf{0})$ & $5(6)$ & $\mathbf{0}(\mathbf{0})$ \\
\hline \multicolumn{5}{|l|}{ Levomepromazine $\left(\right.$ Nozinan $\left.^{\circledR}\right)$} \\
\hline Herbal drugs (Valerian) & $4(2)$ & $\mathbf{0}(\mathbf{0})$ & $3(3)$ & $1(3)$ \\
\hline Melatonin receptor agonists & $2(1)$ & $\mathbf{0}(\mathbf{0})$ & $\mathbf{0}(\mathbf{0})$ & $2(5)$ \\
\hline
\end{tabular}

Table 4 Drug-drug interactions with new sedative prescriptions $(n=156)$

\begin{tabular}{lc}
\hline Interactions & $n(\%)$ \\
\hline Pharmacodynamic & $\mathbf{1 3 6}(\mathbf{8 7})$ \\
Addition of CNS-depressant effects & $123(90)$ \\
Addition of QTc-prolongation effects & $8(6)$ \\
Increased side effects & $5(4)$ \\
Pharmacokinetic & $\mathbf{2 0}(\mathbf{1 3})$ \\
Cytochrome P450 & $18(90)$ \\
Increased the new sedative drug's effects & $12(66)$ \\
Decreased the new sedative drug's effects & $3(17)$ \\
Increased the other drugs' effects & $3(17)$ \\
Unknown mode of action & $2(10)$ \\
\hline
\end{tabular}

CNS central nervous system, QTc corrected QT

\subsection{Sedative Drugs Initiated During Hospital Stay}

During hospital stay, 37\% $(n=108)$ of patients were newly prescribed a sedative drug. The above-mentioned Danish study found similar results (40\%) [38]. Altogether, $62 \%$ of the present study's patients were prescribed at least one sedative drug. In the above-mentioned Belgian study, this proportion was $45 \%$ [24]. Again, this difference might be owing to the general increase in the consumption of sedative drugs over the last decade. However, both the Danish and Canadian studies [6, 38] showed similar percentages (62 and 60\%, respectively) of patients using sedative drugs during their hospitalization to the present one.

Around half (52\%) of new sedative medication prescriptions were recorded within $24 \mathrm{~h}$ of admission. One hypothesis is that these new prescriptions are the result of the sleep disturbances observed in hospitalized patients trying to deal with their particular situation (illness, pain, anxiety, and a hospital setting with noises, lights, and other patients) $[15,14]$. However, this could not be confirmed: it was impossible for our study to know the exact indications for newly prescribed sedative drugs. Nevertheless, whatever the drug's indication, it would probably have a collateral sedative effect. Very few studies have shown that being hospitalized can actually increase sleep disorders; one French study found that this only concerned $16 \%$ of patients [30]. However, another study showed that $9 \%$ of patients used newly prescribed benzodiazepine drugs during their hospital stay [24]. On hospitalization, therefore, a brief intervention by caregivers to explain the situation and reassure patients about their sleeping problems might prove useful and help to avoid the prescription of unnecessary sedative drugs. 
Table 5 Sedative drug prescriptions during hospital stay and at hospital discharge

\begin{tabular}{llcc}
\hline Sedative drugs prescribed & $\begin{array}{l}\text { During hospital stay } \\
(n=161) \\
n(\%)\end{array}$ & $\begin{array}{l}\text { At hospital discharge } \\
(n=53) \\
n(\%)\end{array}$ & $\begin{array}{l}\text { Medication stopped before } \\
\text { discharge } \\
n(\%)\end{array}$ \\
\hline Benzodiazepines & $76(47)$ & $25(47)$ & $51(67)$ \\
Z-drugs & $17(11)$ & $6(11)$ & $11(64)$ \\
Other sedative drugs (clomethiazole) & $51(32)$ & $14(26)$ & $37(73)$ \\
Antidepressants & $6(4)$ & $3(6)$ & $3(50)$ \\
Neuroleptics & $5(3)$ & $2(4)$ & $3(50)$ \\
Herbal drugs & $4(2)$ & $2(4)$ & $2(50)$ \\
Melatonin receptor agonists & $2(1)$ & $1(2)$ & $1(50)$ \\
\hline
\end{tabular}

Table 6 Prevalence of sedative drug prescriptions during hospital stay and at discharge

\begin{tabular}{llc}
\hline $\begin{array}{l}\text { Number of sedative } \\
\text { drugs prescribed }\end{array}$ & $\begin{array}{l}\text { During hospital stay } \\
(n=108) \\
n(\%)\end{array}$ & $\begin{array}{l}\text { At hospital discharge } \\
(n=40) \\
n(\%)\end{array}$ \\
\hline 1 & $76(70)$ & $29(73)$ \\
2 & $18(17)$ & $9(22)$ \\
3 & $12(11)$ & $2(5)$ \\
$>3$ & $2(2)$ & $0(0)$ \\
\hline
\end{tabular}

Benzodiazepines were the most prescribed sedative drugs in the present work, confirming findings from previous studies [16, 25, 31]. The second most prescribed sedative was clomethiazole, a drug prescribed quite frequently in some countries (e.g., the French-speaking part of Switzerland), but not in others (e.g., English-speaking countries). Detailed information on clomethiazole use is thus often missing and no recent studies are available on its use as a sleep disorder medication. However, this drug is an option prescribed for the management of insomnia in preference to benzodiazepines in elderly individuals [41-45]. However, warnings about a risk of respiratory depression have been made, along with the recommendation that the duration of treatment should be short $[1,7,9]$.

Interestingly, the type of sedative drug prescribed changed according to patients' ages. Thus, benzodiazepines (e.g., lorazepam) were mainly prescribed to younger patients $(73 \%$ of sedative drug prescriptions for patients aged under 65 years), whereas clomethiazole was the most prescribed sedative drug for patients aged 65 years or more. This confirmed previous findings from a study conducted at a nearby Swiss university hospital, which showed the high prevalence (64\%) of clomethiazole prescribed to patients aged 75 years or more; this was followed by lorazepam (11\%) [46]. Antidepressants and neuroleptics were not often prescribed in the present study. Indeed, these medications are not recommended as first-line treatments for sleep disorders and should be reserved for patients with specific comorbidities (e.g., depression or psychosis) [47].

\subsection{Medication Review of New Sedative Drug Prescriptions}

At least one DRP was identified in $76 \%$ of cases of newly prescribed sedative drugs. As described above, drug-drug interactions represented the majority of DRPs, classified as either pharmacodynamic or pharmacokinetic [7]. The most frequent pharmacodynamic interaction was the accumulation of the effects of central nervous system depressants. These interactions occurred when sedative drugs were concomitantly prescribed with other drugs with central nervous system-depressant properties, such as opioids, antidepressants, or neuroleptics. The risk of central nervous system-depressant effects was even higher in patients with psychiatric disorders, given the higher proportion of sedative drugs prescribed to this population.

Thirteen percent of drug-drug interactions were pharmacokinetic, mostly owing to drug metabolism by cytochromes. Of particular interest are the interactions between some benzodiazepines/Z-drugs and enzymatic inhibitors; the effects of benzodiazepine drugs can be increased and, consequently, so can their side effects (such as falls and fractures), especially in the elderly [48]. The main sedative drugs involved were clomethiazole, alprazolam, mirtazapine, zolpidem, levomepromazine, and trazodone. Even if specific data on clomethiazole interactions are missing, its metabolism by cytochromes suggests a high potential for pharmacokinetic interactions. [7] 


\subsection{Sedative Drugs at Discharge}

Of the patients prescribed new sedative drugs during their hospital stay, $37 \%(n=40)$ were prescribed the same sedative at discharge. The sedative drugs newly prescribed as PRN were less likely to be continued at discharge than regular prescriptions. One hypothesis is that physicians more frequently re-evaluated PRN prescriptions. These results could be used to improve the prescription of sedative drugs during hospital stays, supporting the prescription of PRN sedative drugs whenever possible.

Clomethiazole, benzodiazepines, and Z-drugs were the types of sedative drugs most frequently stopped at hospital discharge in the present study. This can be explained by the fact that these were the most prescribed drugs during hospital stays. Moreover, two thirds of patients were prescribed only one sedative drug at discharge. The prevalence of multiple-sedative prescriptions was lower than previously reported in the literature.

Overall, hospitalization increased the number of patients prescribed at least one sedative drug by $10 \%$ (comparison of proportions at the beginning and end of hospital stays). In comparison, a previous French study found a 5.4\% increase in the prescription of sedative drugs at discharge [30]. This represents a greater potential risk of long-term sedative use, associated with an increased risk of delirium, falls, daily sedation, memory loss, tolerance, dependence, or withdrawal effects $[7,8,10]$. As mentioned previously, the elderly are most sensitive to these effects.

If sedative drugs are necessary during a hospital stay, physicians should document any new prescription as fully as possible, with case notes including, at the very least, the indication for the new drug, duration of treatment, and precautions for use. Clinical pharmacists can play a key role in such contexts, performing thorough medication reviews and providing recommendations on sedative use.

At discharge, physicians could use clinical pharmacists' recommendations to inform patients about the safe use of sedative drugs, explaining the potential side effects and risks associated with long-term use, encouraging shortterm use, and recommending regular re-evaluations of prescriptions by treating physicians. In this context, ward interventions by clinical pharmacists should reinforce this strategy by increasing the medical staff's knowledge of sedative drugs, proposing clear guidelines for their use, offering alternative measures for managing insomnia during hospitalization, and limiting the long-term use of sedative drugs. After the completion of this study and based on its findings, our hospital launched a Sedative Drugs Project. The program consists of training classes for hospital physicians and nurses, as well as a variety of different information leaflets specially created for physicians, nurses, and patients. The leaflets were created by an interdisciplinary team and contain recommendations on the prevention and management of sleep disorders in the hospital, as well as information on the use of sedative drugs. After a pilot phase involving several wards, the program has now been extended to all of the hospital's wards.

\subsection{Study Strengths and Limitations}

To the best of our knowledge, this study is one of only a few to suggest that hospitals have a significant impact on the subsequent ambulatory prescription of sedative drugs. It provides an accurate illustration of local practices in a Swiss regional hospital, and the number of patients included allowed for a thorough analysis of sedative prescriptions. However, this study reflects sedative prescription practice in only one hospital ward over a limited period of time. Consequently, a generalization of these results should be made with caution.

One limitation of the present study was that it aimed to assess the prescription of sedative drugs, not their actual administration. This implies that the actual exposure to sedative drugs might have been overestimated by taking into account all sedative prescriptions, including the PRN. It therefore reflects a worst-case scenario, i.e., the case where patients took all the sedative drugs prescribed. However, the true administration rates of sedative drugs could not be confirmed because the validation of drug administration is not performed systematically in our hospital's computerized prescribing system. Moreover, although medication reviews were performed, it was usually impossible to know the newly prescribed sedative drug's exact indication. This implies that patients could have been prescribed a sedative drug for reasons other than sleep disorders. However, whatever the indication, if one of these drugs was used in the evening, it would probably have an additional sedative effect. Furthermore, the true use of a sedative drug after discharge and in the long term could not be captured. Once again, these limitations may have led to an overestimation of the use of sedative drugs for sleep disorders.

\section{Conclusion}

This study showed that sedative medication was initiated for $37 \%$ of patients hospitalized in an internal medicine ward of a Swiss hospital. Moreover, at discharge, hospital stays had increased the proportion of patients who received a sedative drug prescription by $10 \%$. These prescriptions may generate long-term sedative drug use and expose patients to DRPs (adverse effects and interactions), which have been shown to be more severe in elderly populations. 
Acknowledgements The authors thank the medical teams from the internal medicine ward for their collaboration and the patients for their participation in this study.

\section{Compliance with Ethical Standards}

Funding This research was solely supported by internal funds.

Conflict of interest Laurence Schumacher, Maria Dobrinas, Damien Tagan, Annelore Sautebin, Anne-Laure Blanc and Nicolas Widmer have no conflicts of interest directly relevant to the content of this study.

Open Access This article is distributed under the terms of the Creative Commons Attribution-NonCommercial 4.0 International License (http://creativecommons.org/licenses/by-nc/4.0/), which permits any noncommercial use, distribution, and reproduction in any medium, provided you give appropriate credit to the original author(s) and the source, provide a link to the Creative Commons license, and indicate if changes were made.

\section{References}

1. Schutte-Rodin S, Broch L, Buysse D, Dorsey C, Sateia M. Clinical guideline for the evaluation and management of chronic insomnia in adults. J Clin Sleep Med. 2008;4(5):487-504.

2. Rogev E, Pillar G. Placebo for a single night improves sleep in patients with objective insomnia. Israel Med Assoc J. 2013;15(8):434-8.

3. Moloney ME, Konrad TR, Zimmer CR. The medicalization of sleeplessness: a public health concern. Am J Public Health. 2011;101(8):1429-33. doi:10.2105/AJPH.2010.300014.

4. Suchtmonitoring. Continuous Rolling Survey on Addictive Behaviours and Related Risks (CoRolAR). 2012. http://www. suchtmonitoring.ch/fr/6.html?somniferes-et-tranquillisants Accessed 9 Sept 2017.

5. Société Vaudoise de Médecine MdfV, Pharmaciens vaudois. Etat de Vaud. Campagne de Prévention: Somnifères? Pas forcément nécessaires! 2013. http://www.vd.ch/index.php?id=53571. Accessed 19 Feb 2015.

6. Frighetto L, Marra C, Bandali S, Wilbur K, Naumann T, Jewesson P. An assessment of quality of sleep and the use of drugs with sedating properties in hospitalized adult patients. Health Qual Life Outcomes. 2004;2:17. doi:10.1186/1477-7525$2-17$.

7. Swiss drugs database 2014-2015. 2015. http://www. swissmedicinfo.ch/. Accessed 9 Sep 2017.

8. Drugs' database with drug-drug-interaction data. 2014. http:// www.uptodate.com/crlsql/interact/frameset.jsp. Accessed 9 Sep 2017.

9. Johnson CF, Frei C, Downes N, McTaggart SA, Akram G. Benzodiazepine and $\mathrm{z}$-hypnotic prescribing for older people in primary care: a cross-sectional population-based study. Br J Gen Pract. 2016;66(647):e410-5. doi:10.3399/bjgp16X685213.

10. Woodward MCCS, Elliott R, Vernon G, Tanner F, Saunders R. Managing insomnia in older people. J Pharm Pract Res. 2007;37(3):236-41.

11. Belknap SM. In adults, use of anxiolytic or hypnotic drugs was associated with increased risk for mortality. Ann Intern Med. 2014;161(2):JC11. doi:10.7326/0003-4819-161-2-201407150-02011.

12. Amarasuriya UK, Myles PR, Sanders RD. Long-term benzodiazepine use and mortality: are we doing the right studies? Curr Drug Saf. 2012;7(5):367-71.
13. Salonoja M, Salminen M, Aarnio P, Vahlberg T, Kivela SL. Onetime counselling decreases the use of benzodiazepines and related drugs among community-dwelling older persons. Age Ageing. 2010;39(3):313-9. doi:10.1093/ageing/afp255.

14. Isaia G, Corsinovi L, Bo M, Santos-Pereira P, Michelis G, Aimonino N, et al. Insomnia among hospitalized elderly patients: prevalence, clinical characteristics and risk factors. Arch Gerontol Geriatr. 2011;52(2):133-7. doi:10.1016/j.archger.2010. 03.001.

15. Nagel CL, Markie MB, Richards KC, Taylor JL. Sleep promotion in hospitalized elders. Medsurg Nurs. 2003;12(5):279-89 (quiz 90).

16. Warie H, Petrovic M, Somers A, Mariman A, Robays H, Pevernagie D. The use of hypnosedative drugs in a university hospital setting. Acta Clin Belg. 2003;58(4):225-32. doi:10.1179/ acb.2003.58.4.003

17. Cunnington D, Junge MF, Fernando AT. Insomnia: prevalence, consequences and effective treatment. Med J Aust. 2013;199(8):S36-40.

18. Jorm AF, Grayson D, Creasey H, Waite L, Broe GA. Long-term benzodiazepine use by elderly people living in the community. Aust N Z J Public Health. 2000;24(1):7-10.

19. Tu K, Mamdani MM, Hux JE, Tu JB. Progressive trends in the prevalence of benzodiazepine prescribing in older people in Ontario, Canada. J Am Geriatr Soc. 2001;49(10):1341-5.

20. Voyer P, Preville M, Cohen D, Berbiche D, Beland SG. The prevalence of benzodiazepine dependence among communitydwelling older adult users in Quebec according to typical and atypical criteria. Can J Aging. 2010;29(2):205-13. doi:10.1017/ s0714980810000115.

21. Elliott RA, Woodward MC, Oborne CA. Improving benzodiazepine prescribing for elderly hospital inpatients using audit and multidisciplinary feedback. Int Med J. 2001;31(9):529-35.

22. Cumbler E, Guerrasio J, Kim J, Glasheen J. Use of medications for insomnia in the hospitalized geriatric population. $\mathrm{J}$ Am Geriatr Soc. 2008;56(3):579-81. doi:10.1111/j.1532-5415.2008. 01598.x.

23. Somers A, Robays H, Audenaert K, Van Maele G, Bogaert M, Petrovic M. The use of hypnosedative drugs in a university hospital: has anything changed in 10 years? Eur J Clin Pharmacol. 2011;67(7):723-9. doi:10.1007/s00228-010-0983-2.

24. Ramesh M, Roberts G. Use of night-time benzodiazepines in an elderly inpatient population. J Clin Pharm Ther. 2002;27(2):93-7.

25. Edwards C, Bushnell JL, Ashton CH, Rawlins MD. Hospital prescribing and usage of hypnotics and anxiolytics. Br J Clin Pharmacol. 1991;31(2):190-2.

26. Smarter medicine, Choosing Wisely Switzerland. 2016. http:// www.smartermedicine.ch/fr/top-5-listen/hospital-care-aim.html. Accessed 17 July 2017.

27. American Geriatrics Society. Ten things clinicians and patients should question. 2013. http://www.choosingwisely.org/societies/ american-geriatrics-society/. Accessed 17 Jul 2017.

28. Choosing Wisely Canada, five things physicians and patients should question. 2014. http://choosingwiselycanada.org/ geriatrics/. Accessed 17 July 2017.

29. Petrovic M, Spatharakis G, Conroy S, Van Maeles G, Moulias S. Prevalence of sedative drug use in geriatric in-patients: a multicentre study. Acta Clin Belg. 2006;61(3):119-26. doi:10.1179/ acb.2006.019.

30. Fagnoni P, Limat S, Haffen E, Henon T, Jacquet M, Sechter D, et al. Does hospitalisation affect hypnotic and anxiolytic drug prescribing? Pharm World Sci. 2007;29(6):611-8. doi:10.1007/ s11096-007-9097-z.

31. Pelissolo A, Notides C, Lepine JP, Bisserbe JC. Anxiolytic and hypnotic use by general hospital inpatients: the impact of 
psychopathology and general medical conditions. Gen Hosp Psychiatry. 1999;21(2):79-86.

32. Ahmad A, Mast MR, Nijpels G, Elders PJ, Dekker JM, Hugtenburg JG. Identification of drug-related problems of elderly patients discharged from hospital. Patient Prefer Adherence. 2014;8:155-65. doi:10.2147/PPA.S48357.

33. Pek EA, Remfry A, Pendrith C, Fan-Lun C, Bhatia RS, Soong C. High prevalence of inappropriate benzodiazepine and sedative hypnotic prescriptions among hospitalized older adults. J Hosp Med. 2017;12(5):310-6. doi:10.12788/jhm.2739.

34. Renom-Guiteras A, Meyer G, Thürmann PA. The EU(7)-PIM list: a list of potentially inappropriate medications for older people consented by experts from seven European countries. Eur J Clin Pharmacol. 2015;71(7):861-75. doi:10.1007/s00228-0151860-9.

35. Drugs' database. 2014. http://www.micromedexsolutions.com/ micromedex2/librarian/CS/8DF27C/PFActionId/pf.HomePage/ ssl/true. Accessed 9 Sept 2017.

36. Vinks TH, de Koning FH, de Lange TM, Egberts TC. Identification of potential drug-related problems in the elderly: the role of the community pharmacist. Pharm World Sci. 2006;28(1):33-8. doi:10.1007/s11096-005-4213-4.

37. GSASA. System for pharmaceutical interventions of the Swiss Association of Public Health Administration and Hospital Pharmacists (GSASA). 2014. http://www.gsasa.ch/pages/activites/ prestation-pharmaceutiques/activites-cliniques/?oid=1587\&lang= FR. Accessed 9 Sept 2017.

38. Moller FT, Andersen SE. Benzodiazepines and cyclopyrrolones prior to, during and after hospital admission. Ugeskr Laeger. 2010;172(21):1602-6.

39. Ballokova A, Peel NM, Fialova D, Scott IA, Gray LC, Hubbard RE. Use of benzodiazepines and association with falls in older people admitted to hospital: a prospective cohort study. Drugs Aging. 2014;31(4):299-310. doi:10.1007/s40266-014-0159-3.

40. Stone KL, Ensrud KE, Ancoli-Israel S. Sleep, insomnia and falls in elderly patients. Sleep Med. 2008;9(Suppl. 1):S18-22. doi:10. 1016/S1389-9457(08)70012-1.

41. Locca JF, Zumbach S, Bula C, Bugnon O. [Management of elderly patients with delirium or dementia in Swiss nursing homes]. Rev Med Suisse. 2007;3(132):2519-20, 22, 24 passim.

42. Overstall PW, Oldman PN. A comparative study of lormetazepam and chlormethiazole in elderly in-patients. Age Ageing. 1987;16(1):45-51.

43. Dehlin O. Hypnotic effect of chlormethiazole in geriatric patients during long-term treatment. Acta Psychiatr Scand Suppl. 1986;329:112-5.

44. Harenko A. A comparison between chlormethiazole and nitrazepam as hypnotics in psycho-geriatric patients. Curr Med Res. 1974;2(10):657-63.

45. Pathy MS, Bayer AJ, Stoker MJ. A double-blind comparison of chlormethiazole and temazepam in elderly patients with sleep disturbances. Acta Psychiatr Scand Suppl. 1986;329:99-103.

46. Von Rohr T RS, Monod S, Büla C, Buclin T, Renard D, et al. Prevalence, incidence and indications of hypno-sedative treatment in hospitalized patients aged 75 and older. CHUV2012 Contract No.: PPH-007.

47. Schmid VS, Frischer U. Troubles du sommeil. PharmActuel, PharmaSuisse. 2014;06:23-4.

48. Zint K, Haefeli WE, Glynn RJ, Mogun H, Avorn J, Sturmer T. Impact of drug interactions, dosage, and duration of therapy on the risk of hip fracture associated with benzodiazepine use in older adults. Pharmacoepidemiol Drug Saf. 2010;19(12):1248-55. doi:10.1002/pds.2031. 